\title{
NÍVEIS DIFERENCIADOS DE GOVERNANCCA CORPORATIVA E GRAU DE CONSERVADORISMO: ESTUDO EMPÍRICO EM COMPANHIAS ABERTAS LISTADAS NA BOVESPA
}

\section{DIFFERENTIAL LEVELS OF CORPORATE GOVERNANCE AND THE DEGREE OF CONSERVATISM: AN EMPIRICAL-STUDY IN THE BRAZILIAN PUBLICLY TRADED COMPANIES LISTED IN BOVESPA}

\author{
JUAN CARLOS GOES DE ALMEIDA \\ Graduando em Ciencias contábeis na FUCAPE \\ E-mail: juan.goes@terra.com.br
}

\author{
RODRIGO SIMONASSI SCALZER \\ Graduando em Ciencias contábeis na FUCAPE \\ E-mail: rodrigoscalzer@yahoo.com.br
}

FÁBIO MORAES DA COSTA

Doutor em Controladoria e Contabilidade pela Universidade de São Paulo

Professor Adjunto da FUCAPE

E-mail: fabio@fucape.br

\section{Resumo}

Neste trabalho, procurou-se identificar se o grau de conservadorismo utilizado pelas empresas que fazem parte dos níveis diferenciados de governança corporativa é diverso/diferente do conservadorismo utilizado pelas demais empresas. Como modelo, aplicou-se o de Basu (1997), que visa identificar a existência de assimetria de reconhecimento entre as notícias boas e as notícias ruins, utilizando, para tanto, o retorno econômico das ações. 0 conservadorismo é uma ferramenta utilizada pela contabilidade com o objetivo de fazer com que as informações contábeis sejam mais confiáveis, tornando a informação menos otimista. Os dados coletados correspondem ao período de 2000 a 2004 e os resultados demonstram que o grau de conservadorismo utilizado pelas empresas que possuem níveis diferenciados de governança corporativa (companhias listadas no Nível 1, no Nível 2 ou no Novo Mercado) é maior do que grau utilizado pelas demais companhias listadas na Bovespa, que não possuem títulos elencados em tais níveis. Como contribuição desta pesquisa, foi possível observar que a contabilidade, utilizando mecanismos como o conservadorismo, pode influenciar os resultados contábeis e, portanto, os resultados encontrados confirmam a existência da assimetria de reconhecimento das notícias boas e notícias ruins no mercado brasileiro.

Palavras-chave: níveis de governança corporativa; conservadorismo; companhias abertas.

\begin{abstract}
This study had the objective to identify if the degree of conservatism used by companies that are part of the differentiated levels of corporate governance is different from the conservatism used by other companies. The model used was that of the Basu (1997) which allows identifying the existence of recognition asymmetry between good and bad news, using the stock market economic return for its purpose. The conservatism is a tool used by accounting with the purpose of making accounting information more reliable and less optimistic. The data obtained was taken between 2000 and 2004 and the results show that the degree of conservatism, used by the companies that have differential levels of corporate governance, (companies listed by Nível 1, Nível 2 or by the Novo Mercado) is higher than that used by other companies listed by Bovespa, which do not have shares listed by such levels. This research made it possible to observe that accounting, using mechanisms as the conservatism, can influence the accounting results and because of that, the results found reaffirm the existence of recognition asymmetry for good and bad news, in the Brazilian market.
\end{abstract}

Key words: levels of corporative governance, conservatism, open companies. 


\title{
INTRODUÇÃO
}

\author{
Segundo Shleifer e Vishny (1997, p. 737-783),
}

a governança corporativa é o campo da administração que trata do conjunto de relações entre a direção das empresas, seus conselhos de administração, seus acionistas e outras partes interessadas. Ela estabelece os caminhos pelos quais os supridores de capital das corporações são assegurados do retorno de seus investimentos.

Para assegurar maior transparência e confiabilidade aos investidores, mecanismos de governança corporativa são implementados, visando proteger os fornecedores de capital de uma possível expropriação por parte dos responsáveis por sua gestão (SHLEIFER e VISHNY, 1997).

Como resultado, espera-se que um maior alinhamento de interesses nas organizações resulte em possíveis reduções de custo de captação e em aumento do valor das companhias (SILVEIRA, 2004).

Seguindo tal movimento internacional, a Bolsa de Valores de São Paulo estabeleceu níveis de governança corporativa para as empresas que possuem títulos negociados.

Dessa forma, os esforços direcionados ao desenvolvimento do mercado de capitais brasileiro resultaram na criação de níveis que exijam um maior comprometimento com as chamadas "boas práticas de governança corporativa".

Assim, foram criadas três classes: Nível 1, Nível 2 e o Novo Mercado, sendo que o Nível 1 tem o menor grau de exigências e o Novo mercado, o maior grau. Por meio de tais níveis seria possível classificar as empresas de acordo com o número de obrigações adicionais à legislação brasileira, incorrendo em uma potencial sinalização para o mercado.

Dentro desse contexto, a contabilidade pode ser entendida como um dos mecanismos relevantes de governança corporativa. Segundo Bushman e Smith (2001), a informação contábil seria um input direto ou indireto para os mecanismos de controle introduzidos nas organizações. Dessa forma, a contabilidade apresentaria uma importante função dentro da estrutura contratual da firma, auxiliando na redução da assimetria de informação e no monitoramento de tais relações (SUNDER, 1997).

Quando abordam a teoria de agência, a assimetria informacional e a divergência de interesses geram os conflitos de agência, Lopes e Martins (2005) afirmam que esses conflitos podem ser reduzidos por meio de informações contábeis que colaborem com uma maior transparência dos acontecimentos ocorridos dentro da empresa.

Os arcabouços conceituais da contabilidade são constituídos de uma série de princípios que procuram direcionar a elaboração de informações úteis para a tomada de decisão. Neste sentido, um dos princípios utilizados para tentar tornar essas informações mais confiáveis é o conservadorismo (BASU, 1997).

Watts (2003a) argumenta que uma das funções do conservadorismo consiste em proteger os fornecedores de capital por limitar ações oportunísticas dos gestores, que muitas vezes possuem parte de sua remuneração, direta ou indireta, atrelada a variáveis contábeis. Sobre tal fato, Lopes e Martins (2005) argumentam que a utilização do princípio do conservadorismo pela contabilidade é fundamental para que a confiabilidade e a transparência fomentadas pela governança corporativa consigam ser atingidas, pois cercearia a ação dos gestores da companhia, os quais apresentariam a tendência de serem otimistas. 
Por outro lado, um conservadorismo excessivo poderia trazer conseqüências adversas, fazendo com que a informação contábil fosse menos oportuna em decorrência de um maior grau de verificabilidade exigido. Sabe-se que a oportunidade é uma restrição existente em arcabouços conceituais como o brasileiro (Deliberação 539/2008) e consiste em uma importante característica da qualidade da informação contábil: seu valor preditivo e seu relacionamento com o comportamento dos preços de mercado (BALL et al., 2000).

Caso haja a aplicação do princípio do conservadorismo, um maior grau de verificabilidade será exigido para o reconhecimento de ativos e receitas, se comparado ao grau exigido para despesas e passivos (WATTS, 2003a). Basu (1997) apresentou evidências empíricas de que existe um maior grau de verificação das notícias ruins em relação às notícias boas pela contabilidade, desenvolvendo um modelo para captar tal reconhecimento assimétrico.

Basu (1997) define que o conservadorismo se apresenta quando há o reconhecimento de más notícias mais oportunamente que o reconhecimento de boas notícias, em relação aos fluxos futuros de caixa. Neste sentido, se o conservadorismo possui uma função contratual, seria possível esperar alguma relação com a estrutura de governança corporativa das entidades (BEEKS et al., 2004). Ahmed e Duellman (2007) apresentam evidências de que as características do conselho de administração possuem relação com o nível de conservadorismo das firmas.

Diante desta afirmativa, e juntamente com os esforços no mercado brasileiro em prol da governança corporativa, é possível apresentar o seguinte questionamento: o grau de conservadorismo utilizado pelas empresas que fazem parte dos níveis diferenciados de governança corporativa é diferente do conservadorismo utilizado pelas demais empresas que não possuem mecanismos de governança?

Assim, o objetivo desta pesquisa consiste em analisar se existe diferença entre o grau de conservadorismo utilizado pelas empresas que fazem parte dos níveis diferenciados de governança corporativa e o grau de conservadorismo utilizado pelas demais empresas listadas na Bovespa que não estão listadas em tais níveis, por meio da aplicação do modelo de Basu (1997).

Portanto, pretende-se relacionar a governança corporativa e o viés supostamente presente nos modelos contábeis: o conservadorismo. Com isso, será possível analisar se as empresas participantes dos níveis estabelecidos pela Bovespa, por terem o emprego de uma maior quantidade de mecanismos de governança corporativa e transparência, divulgariam informações mais conservadoras ao mercado.

\section{NÍVEIS DIFERENCIADOS DA BOVESPA: PRINCIPAIS ASPECTOS}

De acordo com a Comissão de Valores Mobiliários (2006), governança corporativa pode ser definida como sendo um conjunto de práticas que tem por finalidade proteger todos os interessados nos resultados da firma. Na mesma linha, Shleifer e Vishny (1997) definem governança corporativa com um modelo para assegurar aos investidores/acionistas o retorno de seus investimentos realizados na firma.

O IBGC (2006) define governança corporativa como sendo

o sistema pelo quais as sociedades são dirigidas e monitoradas, envolvendo os 
relacionamentos entre Acionistas/Cotistas, Conselho de Administração, Diretoria, Auditoria Independente e Conselho Fiscal. As boas práticas de governança corporativa têm a finalidade de aumentar o valor da sociedade, facilitar seu acesso ao capital e contribuir para a sua perenidade.

Para a Bovespa (2006a), governança corporativa é um esforço para alinhar os objetivos dos administradores com os interesses dos acionistas. Diante disso, a entidade implantou, em dezembro de 2000, níveis diferenciados de governança corporativa que foram desenvolvidos para proporcionar um ambiente de negociação que estimulasse simultaneamente o interesse dos investidores e a valorização das companhias.

As companhias listadas nesses segmentos se comprometem a realizar melhorias nas práticas de governança corporativa, ampliando os direitos dos acionistas minoritários e aumentando a transparência das informações divulgadas ao mercado.

\subsection{NÍVEIS 1 E 2 DE GOVERNANÇA CORPORATIVA}

A adesão das companhias, ao Nível 1 ou ao Nível 2, depende do grau do compromisso assumido e é formalizado por meio de um contrato entre a companhia e a Bovespa. As companhias que estão classificadas no Nível 1 devem apresentar melhorias na prestação de informações ao mercado e promoverem dispersão do controle acionário. Além disso, outras obrigações adicionais à legislação devem ser atendidas, tais como:

- Melhoria nas informações prestadas, adicionando às Informações Trimestrais (ITRs) documento que é enviado pelas companhias listadas à CVM e à BOVESPA, disponibilizado ao público e que contém demonstrações financeiras trimestrais entre outras: demonstrações financeiras consolidadas e a demonstração dos fluxos de caixa.

- Melhoria nas informações relativas a cada exercício social, adicionando às Demonstrações Financeiras Padronizadas (DFPs) - documento que é enviado pelas companhias listadas à CVM e à BOVESPA, disponibilizado ao público e que contém demonstrações financeiras anuais - entre outras, a demonstração dos fluxos de caixa.

- Melhoria nas informações prestadas, adicionando às Informações Anuais (IANs) documento que é enviado pelas companhias listadas à CVM e à BOVESPA, disponibilizado ao público e que contém informações corporativas - entre outras: a quantidade e características dos valores mobiliários de emissão da companhia detidos pelos grupos de acionistas controladores, membros do Conselho de Administração, diretores e membros do Conselho Fiscal, bem como a evolução dessas posições.

- Realização de reuniões públicas com analistas e investidores, ao menos uma vez por ano.

- Apresentação de um calendário anual, do qual conste a programação dos eventos corporativos, tais como assembléias, divulgação de resultados etc.

- Divulgação dos termos dos contratos firmados entre a companhia e partes relacionadas; 
- Divulgação, em bases mensais, das negociações de valores mobiliários e derivativos de emissão da companhia por parte dos acionistas controladores;

- Manutenção em circulação de uma parcela mínima de ações, representando $25 \%$ (vinte e cinco por cento) do capital social da companhia; e

- Quando da realização de distribuições públicas de ações, adoção de mecanismos que favoreçam a dispersão do capital. (BOVESPA, 2006a).

As companhias listadas no Nível 2 comprometem-se a cumprir as exigências estabelecidas para o Nível $1 \mathrm{e}$, adicionalmente, adotam um conjunto de regras mais amplo de práticas de governança, priorizando e ampliando os direitos dos acionistas minoritários. A seguir são apresentadas algumas obrigações adicionais para participação neste nível:

- Divulgação de demonstrações financeiras de acordo com padrões internacionais IFRS (International Financial Reporting Standards) ou US GAAP (United States Generally Accepted Accounting Principles);

- Conselho de Administração com mínimo de 5 (cinco) membros e mandato unificado de até 2 (dois) anos, permitida a reeleição. No mínimo, 20\% (vinte por cento) dos membros deverão ser conselheiros independentes;

- Direito de voto às ações preferenciais em algumas matérias, tais como, transformação, incorporação, fusão ou cisão da companhia e aprovação de contratos entre a companhia e empresas do mesmo grupo sempre que, por força de disposição legal ou estatutária, sejam deliberados em assembléia geral.

- Extensão para todos os acionistas detentores de ações ordinárias das mesmas condições obtidas pelos controladores quando da venda do controle da companhia e de, no mínimo, $80 \%$ (oitenta por cento) deste valor para os detentores de ações preferenciais (tag along);

- Realização de uma oferta pública de aquisição de todas as ações em circulação, no mínimo, pelo valor econômico, nas hipóteses de fechamento do capital ou cancelamento do registro de negociação neste Nível; e

- Adesão à Câmara de Arbitragem do Mercado para resolução de conflitos societários. (BOVESPA, 2006b) 
As companhias listadas nos Níveis 1 e 2 da Bovespa são apresentadas no Quadro 1, a seguir:

\begin{tabular}{|l|l|}
\hline \multicolumn{2}{|c|}{ Companhias listadas no Nível 1} \\
\hline ARACRUZ CELULOSE S.A. & IOCHPE MAXION S.A. \\
\hline ARCELOR BRASIL S.A. & ITAUSA INVESTIMENTOS ITAU S.A. \\
\hline BCO BRADESCO S.A. & KLABIN S.A. \\
\hline BCO ITAU HOLDING FINANCEIRA S.A. & MANGELS INDUSTRIAL S.A. \\
\hline BRADESPAR S.A. & METALURGICA GERDAU S.A. \\
\hline BRASIL TELECOM PARTICIPACOES S.A. & PARTICIPACOES BRASKEM S.A. \\
\hline BRASIL TELECOM S.A. & PERDIGAO S.A. \\
\hline CIA TRANSMISSAO ENERGIA ELET PAULISTA & $\begin{array}{l}\text { RANDON S.A. } \\
\text { PARTICIPAÇÕES }\end{array}$ \\
\hline CIA BRASILEIRA DE DISTRIBUICAO & RIPASA S.A. CELULOSE E PAPELS.A. \\
\hline CIA ENERGETICA DE MINAS GERAIS- CEMIG & SADIA S.A. \\
\hline CIA FIACAO TECIDOS CEDRO CACHOEIRA & SÂO PAULO ALPARGATAS S.A. \\
\hline CIA HERING & SUZANO BAHIA SUL PAPEL E CELULOSE S.A. \\
\hline CIA VALE DO RIO DOCE & ULTRAPAR PARTICIPACOES S.A. \\
\hline CONFAB INDUSTRIAL S.A. & UNIBANCO HOLDINGS S.A. \\
\hline DURATEX S.A. & UNIBANCO UNIAO DE BCOS BRASILEIROS S.A. \\
\hline FABRICA DE PRODS ALIMENTICIOS VIGOR & UNIPAR UNIAO DE IND PETROQ S.A. \\
\hline FRAS-LE S.A. & VOTORANTIM CELULOSE E PAPEL S.A. \\
\hline GERDAU S.A. & WEG S.A. \\
\hline \multicolumn{1}{|c|}{ ComPanhias listadas no NíVEI 2} \\
\hline ALL AMERICA LATINA LOGISTICA S.A. & NET SERVICOS DE COMUNICACAOS.A. \\
\hline CENTRAIS ELET DE SANTA CATARINA S.A. & SUZANO PETROQUIMICA S.A. \\
\hline ELETROPAULO METROP. ELET. SAO PAULO S.A. & TAM S.A. \\
\hline ETERNIT S.A. & UNIVERSO ONLINE S.A. \\
\hline GOL LINHAS AEREAS INTELIGENTES S.A. & VIVAX S.A. \\
\hline MARCOPOLO S.A. & \\
\hline
\end{tabular}

Quadro 1 - Companhias que estão listadas no Nível 1 e Nível 2 (BOVESPA, 2006c)

\subsection{NOVO MERCADO}

O Novo Mercado é um segmento

destinado a empresas que se comprometeram em adotar medidas de governança corporativa, para negociação de ações lançadas pela própria empresa, adicionais às exigidas pela legislação brasileira.

A premissa básica do Novo Mercado, segundo a Bovespa (2006), é “valorização e a liquidez das ações são influenciadas positivamente pelo grau de segurança oferecido pelo direito concedidos aos acionistas e pela qualidade das informações prestadas pelas companhias".

Para fazer parte do Novo Mercado, a empresa deve assinar um contrato no qual se compromete a utilizar um conjunto de regras societárias mais exigentes do que as presentes na legislação brasileira. Esse conjunto de regras é denominado "boas práticas de governança corporativa". Tais regras aumentam os direitos dos acionistas e melhora a qualidade das informações prestadas para os usuários externos.

Uma das principais regras para participar do Novo Mercado é que a firma deve possuir apenas ações ordinárias (são ações que possuem direito de voto). Mas, essa não é a 
única obrigação, sendo que algumas, além de estarem presente no regulamento de listagem, deverão ser aprovadas em assembléias gerais e adicionadas no estatuto social da empresa. A Bovespa cita outras obrigações adicionais que as companhias possuem, são elas:

- Extensão para todos os acionistas das mesmas condições obtidas pelos controladores quando da venda do controle da companhia (tag along).

- Realização de uma oferta pública de aquisição de todas as ações em circulação, no mínimo, pelo valor econômico, nas hipóteses de fechamento do capital ou cancelamento do registro de negociação no Novo Mercado.

- Conselho de Administração com mínimo de 5 (cinco) membros e mandato unificado de até 2 (dois) anos, permitida a reeleição. No mínimo, 20\% (vinte por cento) dos membros deverão ser conselheiros independentes.

Melhoria nas informações prestadas, adicionando às Informações Trimestrais (ITRs) documento que é enviado pelas companhias listadas à CVM e à BOVESPA, disponibilizado ao público e que contém demonstrações financeiras trimestraisentre outras: demonstrações financeiras consolidadas e a demonstração dos fluxos de caixa.

$\square$ Melhoria nas informações relativas a cada exercício social, adicionando às Demonstrações Financeiras Padronizadas (DFPs) - documento que é enviado pelas companhias listadas à CVM e à BOVESPA, disponibilizado ao público e que contém demonstrações financeiras anuais - entre outras, a demonstração dos fluxos de caixa.

$\square$ Divulgação de demonstrações financeiras de acordo com padrões internacionais IFRS ou US GAAP.

$\square$ Melhoria nas informações prestadas, adicionando às Informações Anuais (IANs) documento que é enviado pelas companhias listadas à CVM e à BOVESPA, disponibilizado ao público e que contém informações corporativas - entre outras: a quantidade e características dos valores mobiliários de emissão da companhia detidos pelos grupos de acionistas controladores, membros do Conselho de Administração, diretores e membros do Conselho Fiscal, bem como a evolução dessas posições.

- Realização de reuniões públicas com analistas e investidores, ao menos uma vez por ano.

Apresentação de um calendário anual, do qual conste a programação dos eventos corporativos, tais como assembléias, divulgação de resultados etc.

- Divulgação dos termos dos contratos firmados entre a companhia e partes relacionadas.

- Divulgação, em bases mensais, das negociações de valores mobiliários e derivativos de emissão da companhia por parte dos acionistas controladores.

- Manutenção em circulação de uma parcela mínima de ações, representando 25\% (vinte e cinco por cento) do capital social da companhia.

$\square$ Quando da realização de distribuições públicas de ações, adoção de mecanismos que favoreçam a dispersão do capital.

Adesão à Câmara de Arbitragem do Mercado para resolução de conflitos 
societários. (BOVESPA, 2006d)

No quadro 2, apresentam-se as companhias que estão listadas no Novo Mercado de governança corporativa, de acordo com a classificação da Bovespa (2006e).

\begin{tabular}{l|l}
\hline BCO NOSSA CAIXA S.A. & LIGHT SERVICOS DE ELETRICIDADE S.A. \\
\hline CIA CONCESSOES RODOVIARIAS & LOCALIZA RENT A CAR S.A. \\
\hline CIA SANEAMENTO BASICO EST SÃO PAULO & LOJAS RENNER S.A. \\
\hline CIA SANEAMENTO DE MINAS GERAIS-COPASA MG. & NATURA COSMETICOS S.A \\
\hline COSAN S.A. INDUSTRIA E COMERCIO & OBRASCON HUARTE LAIN BRASIL S.A. \\
\hline CPFL ENERGIA S.A. & PORTO SEGURO S.A. \\
\hline CYRELA BRAZIL REALTY S.A.EMPREEND E PART. & RENAR MACAS S.A \\
\hline DIAGNOSTICOS DA AMERICA S.A. & ROSSI RESIDENCIAL S.A. \\
\hline EDP - ENERGIAS DO BRASIL S.A. & SUBMARINO S.A. \\
\hline GAFISA S.A. & TRACTEBEL ENERGIA S.A. \\
\hline GRENDENE S.A. &
\end{tabular}

Quadro 2 - Companhias listadas no Novo Mercado (BOVESPA, 2006e)

\subsection{CONSERVADORISMO}

Lopes (2005) afirma que a informação contábil existe justamente porque acionistas e administradores não possuem informações homogêneas, onde a informação contábil deve amenizar o conflito de agência e a assimetria informacional.

O conservadorismo é uma das práticas e procedimentos da contabilidade que está presente nas normas do FASB (Financial Accounting Standards Board), do IASB (International Accounting Standards Board), e brasileira (Deliberação CVM 539/2008) e que é amplamente utilizada. No Brasil, a Deliberação CVM 539/2008, quando define a característica qualitativa "confiabilidade", estabelece que a informação deve ser verificável e ser elaborada com prudência.

Em sua revisão sobre a literatura acerca de conservadorismo, Watts (2003a) afirma que usualmente o termo é definido como "as exigências de verificação assimétricas para ganhos e perdas". Tal princípio, portanto, resultaria em um reconhecimento assimétrico entre despesas, passivos, ativos e receitas (BASU, 1997; WATTS, 2003a).

Ao longo dos anos, autores desenvolveram modelos para tentar capturar o fenômeno do conservadorismo contábil (BASU, 1997; GIVOLY \& HAYN, 2000; RYAN, 1995), sendo o de Basu (1997), o mais usualmente empregado (WATTS, 2003b) .

Basu (1997) apresenta evidências de que há conservadorismo em companhias norteamericanas, utilizando dados de 1963 a 1990. Os resultados são similares para empresas britânicas (POPE e WALKER, 1999) e também para as brasileiras (COSTA et al, 2006). Para Ball et al (2000), países classificados como common-law apresentam maior grau de conservadorismo do que países code-law, e tal fato pode estar ligado à existência de maiores incentivos em países desenvolvidos, tais como maior eficiência das cortes e maiores custos de litígios (WATTS, 2003a).

Além do trabalho de Costa et al (2006), que inclui evidências brasileiras, 
outros dois podem ser destacados: Coelho (2007) e Lopes e Walker (2008). Coelho (2007) corrobora os resultados de Costa et al (2006), indicando que o grau de conservadorismo no país é baixo e o grau de conservadorismo condicional é insignificante. Já Lopes e Walker (2008) expandem os resultados de pesquisas anteriores ao argumentarem que estruturas de governança corporativa e listagens em mercados estrangeiros são itens que possuem relação direta com o grau de conservadorismo.

\section{METODOLOGIA}

Para responder a pergunta (se o grau de conservadorismo utilizado pelas empresas que fazem partes dos níveis diferenciados de governança corporativa é diferente do conservadorismo utilizado pelas demais empresas listadas na Bovespa que não possuem mecanismos de governança) será utilizado o modelo de Basu (1997).

O modelo baseia-se na premissa de que o comportamento dos preços das ações no mercado reflete a expectativa dos indivíduos em relação ao futuro da firma (premissa de mercados eficientes). Desta forma, retornos positivos da ação corresponderiam a "boas notícias" e retornos negativos, a "más notícias". Sob o pressuposto da existência de conservadorismo, o modelo contábil seria mais oportuno para o reconhecimento de “más notícias” em relação às "boas notícias". Tal fato é justificado pelo maior grau de verificabilidade exigido para ativos e receitas.

O modelo de Basu (1997), portanto, consiste em uma tentativa de captação da oportunidade da informação contábil, isto é, pelo grau de associação entre o retorno de mercado da ação e o resultado contábil, diferenciando-o para empresas que tiveram retornos negativos versus positivos da ação. Tal fato é possível por meio da inserção de uma variável dummy e sua interação com as outras variáveis.

Assim, será utilizada a equação (1), que permitirá analisar se há alguma diferença no grau de conservadorismo utilizado pelas empresas listadas na Bovespa:

$$
L u c_{i t}=a 0+a 1 \times D_{i t}+a 2 \times R E T_{d i t}+a 3 \times D_{i t} \times R E T_{d i t}
$$

Em que:

Luc $_{\text {it }}=$ Lucro líquido (contábil) da empresa i no ano t.

Dit = variável dummy será 1 se o retorno econômico for negativo e zero para retorno econômico for positivo.

$\mathrm{RET}_{\text {dit }}=$ Retorno econômico em da empresa i no ano t, quatro meses após o encerramento do exercício ( $\left.\mathrm{VM}_{\mathrm{dt}}-\mathrm{VM}_{\mathrm{dt}-1}\right)$.

$\mathrm{VM}_{\text {dit }}=$ Valor de Mercado da empresa i no dia 30 de abril do ano $\mathrm{t}$.

$\mathrm{VM}_{\text {dit-1 }}=$ Valor de Mercado da empresa i no dia 30 de abril do anterior a $\mathrm{t}$.

a1 e a3 = Refletem o reconhecimento assimétrico do retorno econômico, às boas e más notícias, pelo lucro contábil.

a2 = Reflete a oportunidade do lucro contábil, ou seja, o reconhecimento do retorno econômico pelo lucro contábil. 
Utilizou-se a variável dummy para verificar se o lucro contábil é mais sensível aos resultados econômicos negativos que aos resultados positivos.

Segundo Costa e Costa (2005), o coeficiente $a_{2}$ captura o reconhecimento positivo e negativo, em conjunto, do retorno econômico pelo lucro contábil e o coeficiente $a_{3} 0$ resultado negativo, de acordo com as regras e práticas contábeis adotadas pela companhia $\mathfrak{i}$, permitindo a comparabilidade entre as companhias que estão listadas no Nível 1, no Nível 2 e no Novo Mercado das demais companhias listadas na Bovespa.

Os coeficientes $a_{1}$ e $a_{3}$ são definidos como os coeficientes que refletem o reconhecimento assimétrico (Conservadorismo) do retorno econômico pelo lucro contábil. Estes coeficientes permitem atingir o objetivo deste trabalho que é verificar se existem diferenças na aplicação do Conservadorismo (reconhecimento contábil dos resultados econômicos negativos e positivos), entre as empresas listadas no Nível 1, no Nível 2 e no Novo Mercado das demais companhias listadas na Bovespa.

Os dados foram deflacionados pelo próprio software Economática, utilizando o IPCA (Índice Nacional de Preço ao Consumidor Amplo) Acumulado, para valores de 31 de dezembro de 2004. As regressões foram rodadas, utilizando a técnica de dados combinados.

Foram analisados os resultados das regressões rodadas com dados das companhias listadas no Nível 1 , Nível 2 e no Novo Mercado, das demais companhias listadas na Bovespa que não fazem parte do Nível 1, Nível 2 e Novo Mercado, no período de 2000 a 2004. A comparação, porém, não foi baseada na comparação de poderes explicativos em testes como o de Vuong (1989), pois os dados estão combinados (pooled least squares). Assim, as conclusões devem ser avaliadas com cautela.

\subsection{SELEÇÃO DA AMOSTRA E ESTATÍSTICA DESCRITIVA}

Os dados das companhias para o estudo foram coletados do banco de dados do software Economática, no período de dezembro de 2000 até dezembro de 2004 . Esse período foi escolhido devido ao próprio objeto de estudo que é o Novo Mercado, que deve a sua implantação em dezembro de 2000.

Os dados coletados foram o lucro líquido e o valor de mercado no dia 30 de abril, que foram ajustados pelo próprio software Economática pelo IPCA acumulado, em moeda original de 31 de dezembro de 2004.

Foram obtidas 1.351 observações/ano, sendo 280 para empresas que estão listadas nos níveis diferenciados de governança corporativa da Bovespa e 1.071 para empresas que não fazem parte de tais níveis.

\section{RESULTADOS ENCONTRADOS}

Os resultados das regressões realizadas são apresentados em três grupos: para todas as companhias listadas na Bovespa; companhias listadas no Nível 1, Nível 2 ou Novo Mercado; e demais companhias listadas na Bovespa que não fazem parte dos níveis diferenciados de governança corporativa.

A Tabela 1 demonstra os coeficientes $a_{0}, a_{1}, a_{2}, a_{3}$, resultantes das regressões 
das companhias:

Tabela 1 - Resultado da Regressão Utilizando o Modelo de Basu (1997)

\begin{tabular}{l|l|l|l|l}
\multicolumn{4}{c}{ Luc $_{\text {it }}=\mathrm{a}_{0}+\mathrm{a}_{1} \mathrm{D}_{\text {abril }}+\mathrm{a}_{2} \mathrm{RET}_{\text {abril }}+\mathrm{a}_{3} \mathrm{RET}_{\text {abril }} \mathrm{D}_{\text {abril }}$} \\
\hline Nível 1, Nível 2 e Novo Mercado & $\mathrm{a} 0$ & $\mathrm{a} 1$ & $\mathrm{a} 2$ & $\mathrm{a} 3$ \\
\hline Demais companhias & $206801,4^{*}$ & 24449,06 & $0,248245^{*}$ & $0,484131^{*}$ \\
\hline Todas as companhias listadas na Bovespa & 2864,182 & 161432,0 & $0,269604^{*}$ & $0,271027^{*}$ \\
\hline
\end{tabular}

*, ${ }^{* *},{ }^{* * *}$ - Estimativa significativa ao nível de 1\%, 5\% e 10\%, respectivamente.

Luc $_{\text {it }}=$ Lucro líquido (contábil) da empresa i no ano t.

Dit = variável dummy será 1 se o retorno econômico for negativo e zero para retorno econômico for positivo.

RET $_{\text {dit }}=$ Retorno econômico em da empresa i no ano $t$, quatro meses após o encerramento do exercício ( $\left.\mathrm{VM}_{\mathrm{dt}}-\mathrm{VM}_{\mathrm{dt}-1}\right)$.

$\mathrm{VM}_{\mathrm{dit}}=$ Valor de Mercado da empresa i no dia 30 de abril do ano $\mathrm{t}$.

$\mathrm{VM}_{\text {dit-1 }}=$ Valor de Mercado da empresa i no dia 30 de abril do anterior a t.

a1 e a3 = Refletem o reconhecimento assimétrico do retorno econômico, às boas e más notícias, pelo lucro contábil.

a2 = Reflete a oportunidade do lucro contábil, ou seja, o reconhecimento do retorno econômico pelo lucro contábil.

Por meio da análise da Tabela 1 é possível observar que há conservadorismo no mercado acionário brasileiro, seja para todas as companhias, seja para aquelas que fazem parte dos níveis da Bovespa. Tal fato é justificado porque os coeficientes $a_{3}$ de todas as regressões são estatisticamente significativos, os quais correspondem às variáveis dummies que captam o reconhecimento assimétrico entre "notícias ruins" e "notícias boas". Ou seja, o lucro contábil é mais sensível aos resultados negativos que aos resultados positivos, confirmando os resultados encontrados por Basu (1997).

Em termos comparativos, as empresas que participam dos níveis da Bovespa possuem o coeficiente $a_{3}$ no valor de $-0,48$, enquanto as demais companhias do mercado apresentam um coeficiente de -0,27.

Desta forma, os resultados indicam que as companhias que se comprometeram com maiores exigências em termos de mecanismos de governança corporativa (Níveis 1 , 2 e Novo Mercado) apresentariam um maior grau de conservadorismo do que as outras participantes do mercado.

\section{CONSIDERAÇÕES FINAIS}


No presente trabalho foi apresentada uma discussão sobre o viés inserido na contabilidade sobre o reconhecimento dos eventos econômicos ocorridos em uma companhia, conhecido como "conservadorismo contábil". Dessa forma, procurou-se avaliar como o lucro contábil do período incorpora o retorno econômico corrente, avaliando o comportamento diferenciado em relação ao reconhecimento de boas e más notícias.

A base teórica utilizada consistiu na aplicação do modelo desenvolvido por Basu (1997), comparando-se o conservadorismo contábil em empresas participantes dos níveis diferenciados de governança corporativa da Bovespa e as demais companhias abertas brasileiras.

Assim, constatou-se empiricamente que um dos conceitos mais tradicionais da contabilidade - Conservadorismo - está presente no processo de reconhecimento do retorno econômico pelo lucro contábil no mercado acionário brasileiro, corroborando os resultados de Costa et al. (2006).

Especificamente, sobre a comparação das companhias listadas no Nível 1, no Nível 2 e no Novo Mercado versus demais as companhias listadas na Bovespa, foram apresentados indícios de que empresas comprometidas com uma maior quantidade de mecanismos de governança forneceriam informações contábeis mais conservadoras. Portanto, a pesquisa permite observar como a governança corporativa interfere no tipo e na qualidade da informação divulgada ao mercado e se sugere que futuras pesquisas possam investigar as possíveis causas deste fenômeno.

\section{REFERÊNCIAS}

AHMED, A. S. \& DUELLMAN, S. Accounting conservatism and board of director characteristics: An empirical analysis. Journal of Accounting and Economics, v. 43, 2-3, p. 411-437, July, 2007.

BALL, R. J.; KOTHARI, S. P. \& ROBIN, A. The Effect of International Institutional Factors on Properties of Accounting Earnings. Journal of Accounting and Economics, v. 29, p. 1-51, 2000.

BASU, S. The conservatism principle and the asymmetric timeliness of earnings. Journal of Accounting and Economics, 24, p. 3-37, 1997.

BEEKES, W.; POPE, P.; YOUNG, S. The link between earnings timeliness, earnings conservatism and board composition: evidence from the UK. Corporate Governance: An International Review, 12, p. 47-59, 2004.

BOVESPA. Nível 1- Apresentação. Disponível em: <http://www.bovespa.com.br/Principal.asp>. Acesso em: 13 fev. 2006 a.

Nível 2 - Apresentação. Disponível em:

<http://www.bovespa.com.br/Principal.asp>. Acesso em: 13 fev. $2006 \mathrm{~b}$.

Nível 1 - Companhias Listadas. Disponível em $<$ http://www.bovespa.com.br/Home/Redirect.asp?end=/Empresas/InformacoesEmpresas/Exe cutaAcaoConsultaNivelGovernanca.asp?nivel=n1 >> . Acesso em 13 fev. 2006c.

Novo mercado - Apresentação. Disponível em: <http: //www.bovespa.com.br/Principal.asp> . Acesso em 13 fev. 2006d. 
Novo Mercado - Companhias Listadas. Disponível em: < http://www.bovespa.com.br/Home/Redirect.asp?end=/Empresas/InformacoesEmpresas/Exe cutaAcaoConsultaNivelGovernanca.asp?nivel=nm >> . Acesso em 13 fev. 2006e.

BUSHMAN, R. M. \& SMITH, A. J. Financial Accounting Information and Corporate Governance. Journal of Accounting and Economics, v. 32, 1-3, p. 237-333, 2001.

COELHO, A. C. D. Qualidade Informacional e Conservadorismo nos Resultados Publicados no Brasil. São Paulo: 2007. Tese (Doutorado em Controladoria e Contabilidade). Universidade de São Paulo - Faculdade de Economia, Administração e Contabilidade, São Paulo, 2007.

COMISSÃO DE VALORES MOBILIÁRIOS. Cartilha de Governança Corporativa. Disponível em: <http://www.cvm.gov.br/port/public/publ/cartilha/cartilha.doc>. Acesso em: 13 fev. 2006.

COSTA, A. C. O.; COSTA, F. M. Um Estudo da Aplicação do Conservadorismo em Cinco Países da América do Sul. In: Enanpad. 2005. Brasília - DF. Anais ... Brasília - DF: ANPAD, 2005.

GIVOLY, D \& HAYN, C. The Changing Time-series Properties of Earnings, Cash Flows and Accruals: has financial reporting become more conservative? Journal of Accounting and Economics, v. 29, p. 287-320, Aug. 2000.

IBGC - Instituto Brasileiro de Governança Corporativa. Disponível em <http: //www.ibgc.org.br> Acesso em 14 fev.2006.

LOPES, A. B.; Martins E. Teoria da Contabilidade: Uma Nova Abordagem, São Paulo: Atlas, 2005.

POPE, P. F. \& WALKER, M. International Differences in the Timeliness, Conservatism, and Classification of Earnings. Journal of Accounting Research, v. 37, p. 53-87, 1999.

RYAN, S. G. A Model of Accrual Measurement with Implications for the Evolution of the Book-to-Market Ratio. Journal of Accounting Research, v. 33, 1, p. 95-112, Spring, 1995.

SHLEIFER, A. \& VISHNY, R. W. A Survey of Corporate Governance. The Journal of Finance, v. LII, 2, p. 737-783, jun. 1997.

SILVEIRA, A. D. M. Governança Corporativa e Estrutura de Propriedade: determinantes e relação com o desempenho das empresas no Brasil. São Paulo, 2004. Tese (Doutorado em Administração). Universidade de São Paulo - Faculdade de Economia, Administração e Contabilidade. São Paulo, 2004.

SUNDER, S. Theory of accounting and control. Ohio: South-Western College Publishing, 1997.

WATTS, R. L. Conservatism in Accounting Part I: explanations and implications. Accounting Horizons, v. 17, 3, p. 207-221, Sep. 2003a.

WATTS, R. L. Conservatism in Accounting Part II: evidence and research opportunities. Accounting Horizons, v. 17, 4, p. 287-301, Dec. 2003b. 


\section{ENDEREÇO DOS AUTORES}

Fundação Instituto Capixaba de Pesquisa em Contabilidade, Economia e Finanças Av. Fernando Ferrari, 1358 - Goiabeiras

Vitoria, ES - Brasil

29075-010 